Diánoia, vol. 20, no. 20, 1974

\title{
NUEVAMENTE HERÁCLITO
}

Suponiendo que un texto se nos ofrezca para ser interpretado -es posible concebir un texto sin interpretación, un texto, por así decirlo, tal cualel texto múltiple y fragmentado de Heráclito es laberíntico y enigmático. No es esta la ocasión para narrar las diversas versiones que del pensamiento de Heráclito se han dado. Recordemos tan sólo las de Oswald Spengler, quien ve en Heráclito al filósofo de la "fuerza" y de la "energia", a Theodor Gomperz, quien lo incluye "entre los naturalistas jonios", a John Burnett, quien resalta el aspecto religioso de los fragmentos, a Machioro, quien percibe en ellos la influencia de los órficos.

Ya lo decía Spengler: "no existe probablemente explicación sobre la doctrina del Oscuro de Éfeso que no se haya intentado ya". ${ }^{2}$

¿Por qué intentar una nueva lectura de Heráclito y, sobre todo, qué puede aportar esta lectura a las que se han hecho en el curso de la historia, de San Justino Mártir a nuestros días? Dos motivos: recientemente, en un libro brillante, Clémence Ramnoux - lo veremos- ofrece una interpretación del "logos" que me parece a la vez admirable y criticable; por otra parte creo percibir en la combinatoria de signos (agua, fuego, sol) algunas novedades que intento descifrar por medio de lo que llaman los estilistas "constantes imaginativas", aun cuando éstas sean pocas en Heráclito precisamente por la escasez de sus fragmentos.

Es ya clásico considerar a Heráclito como el filósofo del movimiento. $Y$, en efecto, algunas de sus frases, algunas de sus alegorías abreviadas en metáfora, sinécdoque, paralelismo similar al que Jakobson encuentra en la poesía, parecen sugerir que Heráclito fue el pensador de la mutabilidad. Sabemos, por otra parte, que Heráclito no fue solamente eso; fue también el pensador del logos, así como el filósofo de la unidad de los opuestos y del ciclo de los eternos retornos. Me permito una breve presentación de este Heráclito algo escolar. Más adelante discutiré los dos temas que he enunciado y anunciado.

Heráclito hace resaltar el cambio del universo sensible en imágenes muchas veces citadas. En el fragmento 12 escribe: "a los que ingresan en los mismos ríos sobrevienen otras y otras aguas..." Las aguas, el mundo, las criaturas pasan sin cesar. ¿Qué sucede con el hombre? La respuesta ha de encontrarse en el fragmento 49 donde lapidariamente Heráclito dice: "En los mismos ríos ingresamos y no ingresamos, somos y no somos." Pasan sin

1 Este breve estudio forma parte de un libro relativamente amplio que de momento lleva por título: Hipótesis sobre el desarrollo de la filosofia en Occidente.

2 Cfr., el indispensable Heráclito de Mondolfo, Siglo XXI, México, 1968. 
cesar las criaturas, pero pasan sin cesar también los hombres puesto que son ellos los que corren como corren las aguas del río. Nuestro mundo es el mundo del cambio - somos y no somos al dejar de ser lo que nunca alcanzamos a ser. Este cambio se explica - lo habia visto ya Anaximandropor la existencia de opuestos. Hasta aquí el Heráclito más conocido y el que mayor influencia tuvo en un futuro relativamente cercano. Platón hará decir a Protágoras - lejano discípulo de este Heráclito del movimiento y de los cambios- que no existe ningún conocimiento absoluto puesto que todo lo que percibimos cambia del mismo modo que cambian nuestras percepciones de los objetos.

Este Heráclito es menos de la mitad de lo que Heráclito fue. No hay duda de que para él existen los cambios y las mudanzas; no hay duda tampoco de que para él el cambio que se realiza entre los opuestos se anula y disuelve cuando vemos que los opuestos pactan. En una ocasión este pacto llamado aquí "armonía" (¿palabra de origen órfico?) conduce a una aseveración contundente: "Lo que se opone es concorde, y de lo discordante [se forma] la más bella armonía y todo se engendra por la discordia" (fragmento 8). ¿Es "discorde” el mundo de los seres sensibles? Es probable que así sea cuando vemos, si ahondamos en el sentido de los opuestos y de su concordancia final que no hay armonía si no hay "agudo" y "grave", "macho" y "hembra". Más claramente, quien piensa que los opuestos son irreconciliables y que el universo es puro movimiento, no tiene verdadero conocimiento. El saber auténtico es el que nos dice: "No comprenden cómo lo divergente converge consigo mismo: armonía de tensiones opuestas como del arco y la lira" (fragmento 51). Quien posea la sabiduría sabrá no sólo que los opuestos se unen, sino que esta unión es tensa, es decir -y aquí voy de acuerdo con Spengler- es una energía que nada tiene que ver con una inmovilidad pura y abstracta.

Entre los ignorantes - clara reacción del pensador que es Heráclito contra las falsedades de los poetas _ está "el maestro de los más", Hesíodo, "que ni siquiera conoció el día y la noche; pues son una sola cosa" (fragmento 57). No es siempre ajeno al pensamiento de Heráclito cierto relativismo moral - "bien" y "mal" son una sola cosa (fragmento 58) —, relativismo que no dejará de influir en Nietzsche. Pero, en el fondo de su búsqueda - "me he buscado a mi mismo" (escribe en el fragmento 101) - encuentra, con paz de ánimo que "el camino hacia arriba y el camino hacia abajo son uno solo y el mismo" (fragmento 6o). Interesa recordar aquí que el oráculo de Delfos era perentorio: "¡Conócete a ti mismol" Heráclito no sabe si alcanzará a conocerse y si se busca es porque "los límites del alma, por más que procedas, no lograrás encontrarlos aun cuando recorrieras todos los caminos, tan hondo tiene su logos" (fragmento 45).

De imagen en imagen hemos llegado a lo que con Guthrie (History of 
Greek Philosophy, I) considero el centro y meollo vivo del pensar de Heráclito: el Logos, la Palabra, la Razón.

Ciertamente es importante la teoría de Heráclito acerca del eterno retorno, pero no es una teoría o imagen del mundo novedosa: se encuentra no sólo en las religiones de la India, sino en la filosofía de los primitivos. ${ }^{8}$ Lo que importa es señalar que el ciclo heraclíteo va del fuego al fuego, elemento que después analizaré en relación al Logos, la Palabra, la Razón.

Pero, ¿qué es el Logos? Vayamos a las fuentes. Veamos primero lo que Heráclito tiene que decir acerca del Logos - y no tanto del Logos_, recordando, primero la gran variedad de significados que la palabra tenía en el siglo v. Guthrie —en la obra arriba citada - señala que Logos significaba, según autores, textos y contextos: cualquier cosa dicha, reputación, fama, reflexión, causa, razón, verdad, medida, correspondencia, principio, regla, algo oido y aun rumor o chisme o, en algunos casos, habla engañosa. ${ }^{4}$.

Pero, ¿qué dice Heráclito acerca del Logos; ¿cómo debe interpretarse lo que dice?

Sabemos ya que el Logos está en lo más profundo del alma y que es tan vasto que no lograremos asirlo ni comprenderlo nunca del todo. En algunos casos, Logos parece significar "medida"; así, cuando al referirse al eterno fuego viviente que es el universo, nos dice Heráclito que "se enciende y se apaga según medida" (fragmento 30). Sabemos además que la palabra "fuego" es un símbolo del Logos y, por lo mismo que el Logos en su misma natuarleza es medida. ${ }^{5}$ Pero sabemos, sobre todo que el Logos no es una presencia inventada por Heráclito: "no escuchándome a mí sino al Logos, sabio es que reconozcas que todas las cosas son uno" (fragmento 5o). Por lo demás "es propio del alma un Logos que se acrecienta a sí mismo" (fragmento 115). Razón del alma, el Logos es también el principio que permite que el alma posea ésta su razón.

En otras palabras el Logos —esencia de la mente- es además real. Así lo dice el fragmento 1: "Aun siendo este Logos real los hombres son incapaces de comprenderlo antes de haberlo oído y después de haberlo oído por primera vez. Pues a pesar de que todo procede conforme a este Logos, ellos se parecen a los carentes de experiencia, al experimentar palabras y acciones como las que yo expongo, distinguiendo cada cosa de acuerdo con su naturaleza y explicando cómo es. En cambio a los demás hombres se les escapa cuanto hacen despiertos al igual que olvidan cuanto hacen dormidos."

3 Véase sobre todo Mircea Eliade: El mito del eterno retorno (Alianza Editorial, Madrid, 1970) y sobre todo, From Primitive to Zen (Collins, Londres, 1967).

4 W. C. Guthrie dedica cinco páginas de su historia de la filosoffa griega a presentar los distintos sentidos de "logos" en el siglo xv. Guthrie, a su vez, resume el estudio filológico de la palabra por H. Boeder.

${ }_{5} \mathrm{La}$ identificación fuego-logos es aceptada por casi todos los comentaristas de Heráclito. 
El Logos vivo, tan fundante como este elemento que todo lo penetra -el fuego-, preside el universo natural y humano en sus eternos retornos de fuego a fuego, de purificación a purificación.

Como Clémence Ramnoux en Heraclite ou l'homme entre les choses et les mots (Les Belles Lettres, París, 1968) da una interpretación distinta del Logos de Heráclito, conviene, por su penetración, resumirla brevemente.

El mérito de Clémence Ramnoux reside principalmente en haber situado a Heráclito en su tiempo. Contra muchos de los historiadores de la filosofía griega que encuentran una "fisura infranqueable entre Hesíodo y Heráclito", Clémence Ramnoux postula "...que algo hay que ganar si se leen las antiguas sabidurías relacionándolas a su sustrato cultural". Este sustrato es fluido y fluido el significado de las palabras. Tomemos como ejemplo la palabra Noche; en diversos momentos sucesivos significa:

a) una "epifanía nocturna" que rige "los ritos nocturnos";

b) una palabra derivada de la primera, referida a una profetisa, una madre, una reina;

c) tan sólo una palabra, aun cuando ésta conserve cierto valor de "encantamiento";

d) tan sólo una palabra con residuos de "poderio" (adivinación, formación de nuevos significados);

e) una palabra como cualquier otra; palabra "desmitificada" que remite a "la noche de todas las noches";

f) un sentido filosófico, forzando a veces el sentido de la palabra.

Clémence Ramnoux sitúa la obra de Heráclito entre los significados $c$ y $e$ (sentido mágico, sentido que implica poderío y sentido, por así decirlo, literal).

Este esquema, interesante como es, no parece ir suficientemente lejos. Es probable que las palabras de Heráclito conserven una tonalidad místicoreligiosa; por otra parte, en el fragmento 1 la palabra Logos es referencia a un ser trascendente que, en forma intelectiva y oracular, hizo decir desde antiguo que Heráclito era oscuro - lo cual, por lo menos a mí, me consuela de que solamente queden los fragmentos que quedan y no el libro que acaso escribió.

Clémence Ramnoux piensa que la escuela de intérpretes germánicos hace resaltar los aspectos mítico-místicos de Heráclito, mientras que los historiadores británicos, más empíricos, hacen resaltar el aspecto didáctico de los textos. No creo que esta escisión sea del todo certera. Por lo menos Cornford y Guthrie, entre los anglosajones tienden a una visión, por así decirlo, "germánica", de Heráclito. ${ }^{6}$

- La limitación de Clémence Ramnoux procede de analizar a un solo anglosajón (Kirk) y a un solo alemán (B. Snell). 
Clémence Ramnoux, para precisar el significado de Logos, retradúce el primer fragmento en estas palabras que, a mi vez, retraduzco del francés:

"Este Logos, tal como me lo da la lección, es. Los hombres quedan siempre sin oírlo y aun antes de que lo hayan oído y después de haberlo escuchado por primera vez, todas las cosas del mundo nacen y mueren según el Logos, pero los hombres parecen carentes de experiencia aun cuando hacen la experiencia de los trabajos citados, tal como yo los expongo recortando cada cosa según su naturaleza y arreglando los signos para decir la cosa como es. Por lo que toca a los otros hombres, se les escapa lo que hacen despiertos de la misma manera que olvidan lo que hacen dormidos."

Como cualquier palabra moderna traduce mal la palabra, Logos (cuenta, medida, relación, proporción, palabra, discurso, enunciado...) Clémence Ramnoux propone conservar "logos" en francés y hacer derivar los demás sentidos de la palabra en otros fragmentos de este "logos" intraducido por intraducible.

Es razonable conservar la palabra Logos en las lenguas modernas. Lo que no parece claro es que Logos signifique en algunos contextos "lección". Si Logos, metafóricamente "fuego", conserva una fuerte carga de significados mítico-religiosos, hay que conservarlos también; oír y escuchar la lección es oir y escuchar al Logos que todo lo preside y penetra. Algo tiene, en efecto -así lo piensa Clémence Ramnoux — de Leyenda esta palabra Logos; y, podría añadirse, algo hay en ella de "Ley". El Logos, principio o causa, es tam. bién Ley y Leyenda.

Tal parece ser la "lección" que podemos sacar de la doctrina de Heráclito. Me gustaría añadir, para aclarar más el sentido mítico-religioso de este pensamiento, el significado probable de dos elementos que los fragmentos repiten: agua, fuego.

No quiero generalizar, pero en el conjunto de los textos de Heráclito ciertos aspectos de lo acuoso suelen designar lo negativo; el fuego, lo positivo y, en última instancia, la razón de ser - el Logos - de lo positivo mismo.

Dos ejes: el de lo que pertenece al fuego, el de lo que pertenece al agua.

Sabemos, por el fragmento 6 que "el sol sería nuevo cada día" y por el fragmento 16 que no podemos ocultarnos de él "porque no tiene ocaso". Así el sol es, renovadamente, acto creador, nacimiento, renacimiento, pero es también presencia ("eternamente vivo", en el fragmento 3o). Desde un punto de vista ético se nos dice que el fuego es "juez" (fragmento 66) y que el alma "seca" es la más sabia (fragmento 119). Fuego y sol no coinciden del todo, puesto que el fuego-logos preside a los significados y signos del sol. No se oponen fuego y noche; lo que se opone al sol es la noche.

Por otra parte, algunas cualidades acuosas se oponen tanto al sol como al fuego-logos; resistencia en el universo ante la fuerza creadora de la Ra- 
zón, la Ley, la Palabra, la Medida. Ciertamente, del agua pura surgen las almas (fragmento 12). El agua no es siempre negatividad. Pero lo es cuando adquiere cualidades de humedad pura: "Para las almas es placer o muerte volverse húmedas" (fragmento 77 que no hay que interpretar necesariamente como, a veces se ha hecho, condenación de la borrachera). En esta frase, la humedad, opuesta a la sequedad antes citada, se alía al placer, para sembrar la semilla de una filosofía ascética que niega el valor de los placeres. Es negatividad también el agua cuando, unida a la tierra, produce el cieno: "los cerdos gozan con el cieno más que con el agua pura" (fragmento 13).

¿Es posible establecer una escala de los elementos y sus derivados?

Podria, en efecto, ser ésta:

En la cima, el Logos que es el "fuego" (en una ocasión sustituido por el oro que se busca sin encontrarlo después de cavar mucho); el sol, con todas las connotaciones de novedad (el sol es nuevo cada día) y de presencia (el sol es el mismo cada día); el agua que puede ser agua pura y lugar de nacimiento de las almas; los derivados del agua (humedad, cieno), expresiones del placer y del vicio.

Pero, ¿qué hacer con los ríos que pasan de tal manera que no podemos entrar en ellos dos veces o acaso ni una sola vez, como pensará aígún discipulo de Heráclito?

Arriesgo una hipótesis: si Heráclito es esencialmente el pensador del Logos, de la Ley, de la Armonía (¿reminiscencia órfica?), el agua de los ríos se convierte en un hecho: el paso del tiempo, el camino de la vida, río que va a dar a la mar, que es el morir y solamente adquiere sentido místicamente en la unión de los opuestos: en este camino que, hacia arriba, hacia abajo, es uno y es el mismo.

Hegel y después Marx encontraron en Heráclito un maestro. Creo dudoso que exista en Heráclito una dialéctica trinitaria en el sentido que la pälabra adquiere a partir de Fichte, Schelling, Hegel.

Heráclito vive y nos hace vivir en los sf́mbolos-palabra. La unión de los opuestos nos conduce a viejas reminiscencias - unión de opuestos en el pensamiento, mágico-místico- y a nuevas presencias: la unión de los opuestos en la contemplación mística sea la de Plotino, la del maestro Eckhart, la de Nicolás de Cusa, la de Jacob Boehme, el zapatero.

Este Heráclito místico-racional sé acerca a San Juan Evangelista, cuyo Evangelio no es el último de los cuatro evangelios sino, según demostraciones recientes, el primero. El primero que usa la palabra Verbum que, como Clémence Ramnoux en el caso del Logos, me niego a traducir al castellano.

RAMón XIRAu

INSTITUTO DE InVESTIGACiones FILOSÓfICAS

Universidad Nacional Autónoma de MÉxico 